\title{
Commentary on "Homogeneous nucleation of NAD and NAT in liquid stratospheric aerosols: insufficient to explain denitrification" by Knopf et al.
}

\author{
A. Tabazadeh \\ NASA Ames Research Center, Earth Science Division, Moffett Field, CA 94035
}

Received: 30 December 2002 - Published in Atmos. Chem. Phys. Discuss.: 14 February 2003

Revised: 4 June 2003 - Accepted: 6 June 2003 - Published: 24 June 2003

In a recent published paper Knopf et a1. (2002) have suggested that the homogeneous freezing behavior of stratospheric aerosols, under polar winter conditions, can be simulated experimentally in large bulk phase-sized droplet samples $(0.12-0.27 \mathrm{~cm}$ in diameter). Their hypothesis is based on the fact that a nucleus, which freezes the supercooled phase, forms within the bulk volume of a given sample, and therefore, if large bulk volumes don't freeze in the laboratory, then small volumes in particles most certainly remain unfrozen in the stratosphere. The important question to ask here is whether their initial hypothesis, which they have used to analyze their data, is even correct to begin with. For example, does a nucleus, which turns over the phase, forms within the bulk volume or on the surface of the supercooled phase? Some recent studies provide both experimental (Tabazadeh et al., 2002a, b) and theoretical (Djikaev et al., 2002, 2003) support for the formation of the nucleus at the surface of a supercooled droplet. If the homogeneous nucleation process initiates at the droplet surface, then the approach taken by Knopf. et al. to study this crystallization process may not be directly applicable to the stratospheric situation.

First, in Fig. 1 the percentage of molecules residing on the surface of a given size sample, relative to the total number of molecules present in the entire sample, is shown. In the following calculations, sample surfaces were assumed to be fully coated by a layer of surface-active molecules. The monolayer assumption is a pretty reasonable one to make here based on published literature data on what is known about organic films on surfaces of aerosol and cloud particles in the troposphere (Gill et al., 1983; Facchini et al., 2000). For a monolayer assumption of surface-active molecules, the arrow in Fig. 1 indicates that only $0.0005 \%$ of molecules in the Knopf et al. sample resided on the surface. This calculation shows that the presence of only $0.0005 \%$ of a surface-

Correspondence to: A. Tabazadeh

(Azadeh.Tabazadeh-1@nasa.gov) active component in their samples could have contaminated the surface layer and thus prevented the nucleation from occurring at this interface. Surface-active components preferably partition into the surface layer of an aerosol particle instead of dissolving within its bulk volume. Such components are often made of longer chain hydrocarbons and relatively higher molecular weight oxygenated organic molecules (Gill et al., 1983). If homogeneous freezing initiates at the droplet surface (Tabazadeh et al., 2002a, b), then the surface tension at the air-solution interface is what ultimately controls the overall rate of the nucleation process. Thus, slight contamination by molecules, which preferably partition into the surface layer, can dramatically hamper the rate of the nucleation process. Since Knopf et al. have provided no experimental evidence to show that trace amounts of "sticky" surface-active molecules were not present in their samples at such low levels $(<0.0005 \%)$, it is hard to imagine that their surfaces were pure enough to study this crystallization process. On the contrary, careful composition analysis of aerosols generated in the laboratory indicates that they often contain organic impurity (Middlebrook et al., 1997). Figure 1 also shows that if this crystallization process is studied using submicron particles, then significant fractions of surface active components are needed to deactivate the surface from freezing into hydrates of nitric acid. For example, for a 0.1 micron particle, roughly $5 \%$ of a surface-activate component is needed to fully contaminate the surface layer. Thus, one can see through this illustration the power of conducting freezing experiments, using small particles instead of bulk-sized samples because it will be nearly impossible to purify bulk samples to a point where "sticky" surface-active organic molecules become rare entities at the surface layer. Of course, such "sticky" organic molecules that are present near the surface of the Earth, and perhaps in the environment of a terrestrial laboratory (Middlebrook et al., 1997), are relatively scarce molecules to stick to the surfaces of pristine cloud droplets in the winter polar stratosphere. 


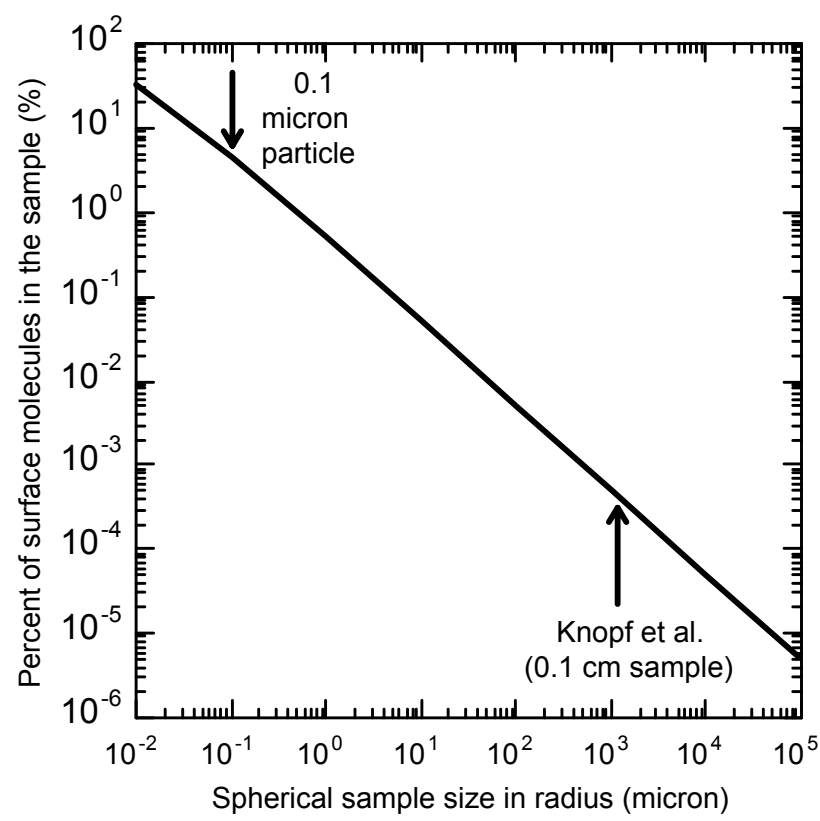

Fig. 1. The percentage of molecules residing on the surface for a given size sample. To calculate the number of molecules in the bulk, a density of $1.3 \mathrm{~g} \mathrm{~cm}^{-3}$ was assumed. A molecular weight of 63 grams mol $^{-1}$ was used in the bulk calculations. To calculate the number of molecules on the surface a site density of $10^{15} \mathrm{~cm}^{-2}$ was assumed.

Second, it seems that the Knopf et al. study does not account for the fact that the surface layer has a different chemical composition than that of the bulk phase, mainly due to stronger surface adsorption of some components relative to others. Specifically, it has been shown that molecular nitric acid is enriched at the surface layer of aqueous solutions (Donaldson and Anderson, 1999; Yang and Finlayson-Pitts, 2001). Furthermore, our recent study (Djikaev et al., 2003) also shows that the level of surface enrichment of a given species in a multicomponent solution is a function of particle size. Thus, even if the bulk samples of Knopf et al. had pristine surfaces (the authors don't present any direct evidence of contamination on bulk samples), the surface layer of a bulk sample may have a different chemical composition than that of an "actual" submicron particle in the stratosphere. If the homogeneous nucleus forms at the surface of a droplet (Tabazadeh et al., 2002a, b), then different surface properties in the laboratory versus the stratosphere can, in principle, yield different results.

My main purpose for writing this letter is to advocate a need for quantitative experimental data on the freezing process of the stratospheric particle system. Such particle systems in the stratosphere are highly supercooled and they must freeze into hydrates of nitric acid if they are observed for long enough periods and if enough care is exercised in the laboratory to prepare pristine supercooled droplet samples that are representative of the real atmosphere. It is essential that the rate of the stratospheric cloud freezing process is quantified through careful laboratory experiments. Once the rates are known quantitatively, then one can truly examine whether this system will freeze homogeneously or not in the polar stratosphere. Such firm conclusions, as stated in the title and the abstract of the Knopf et al. paper, are not warranted because the experimental procedure used is not up to the task to methodically and carefully examine this homogeneous freezing process. If homogeneous rates obtained from future laboratory experiments turn out to be too slow, then the next step is to look into possible heterogeneous pathways for this nucleation process, involving ice or perhaps other types of solid surfaces.

Finally, it is important to point out that the homogeneous nucleation rate functions in the Salcedo et al. (2001) and Tabazadeh et al. papers $(2001,2002 b)$ are most likely not applicable to the stratosphere because the fitted rates may only be valid for concentrated binary solutions of nitric acid and water. The stratospheric system is a ternary solution and the solute mass is more dilute in nitric acid. Thus, future targeted laboratory work, where relevant solution compositions are used, are indeed needed to make further progress in this area. Too many experimental and theoretical papers have been written on this subject, speculating possible formation freezing scenarios, and only carefully designed and executed future submicron "particle" laboratory experiments can properly address this lingering decadeold problem. It has been known since 1993 (Molina et al.) that bulk-sized samples, containing supercooled solutions of $\mathrm{H}_{2} \mathrm{SO}_{4}-\mathrm{HNO}_{3}-\mathrm{H}_{2} \mathrm{O}$, don't freeze for many hours while held at cold polar stratospheric temperatures, a finding which is identical to the one presented in the Knopf et al. paper a decade later. The only conclusion that can be drawn from bulk phase studies is that the rate of freezing in the bulk is negligible, and no conclusion can be drawn regarding the rate of freezing into hydrates of nitric acid at the surface layer of a "real" pristine submicron stratospheric aerosol particle. I hope we all agree that it is the latter process, which may be of some interest here, and not the former one that has been studied repeatedly in the laboratory over the last decade, yielding basically the same somewhat not-so-useful conclusion.

Acknowledgements. I thank Thomas Koop for inviting me to join the online discussion regarding this paper. Unfortunately, at the time I was too preoccupied and could not write an interactive report on this paper. However, I did provide copies of our (then) in press manuscripts (now published in Journal of physical chemistry) to Thomas Koop. Thus the information, upon which most of this commentary is based on, were made available to the authors of the Knopf et al. paper prior to the formal publication date of their manuscript. 


\section{References}

Djikaev, Y., Tabazadeh, A., Hamill, P. and Reiss, H.: Thermodynamic conditions for the surface-stimulated crystallization of atmospheric droplets, J. Phys. Chem. A, 106, 10 247-10 253, 2002.

Djikaev, Y., Tabazadeh, A., and Reiss, H.: Thermodynamics of crystal nucleation in multicomponent drops: The effects of surface adsorption and dissociation, J. Chem. Phys., 118, 65726581, 2003.

Donaldson, D. J. and Anderson, D.: Does molecular nitric acid adsorb onto sulfuric acid droplet surfaces? Geophys. Res. Lett., 26, 3625-3628, 1999.

Facchini, M. C., Decesari, S., and Mircea, M.: Surface tension of atmospheric wet aerosol and cloud/fog droplets in relation to the organic carbon content and chemical composition, Atmos. Env., 34, 4853-4847, 2000.

Gill, P. S, Graedel, T. E., and Weschler, C. J.: Organic films on atmospheric aerosol particles, fog droplets, cloud droplets, raindrops, and snowflakes, Rev. Geophys. Space Phys., 21, 903-920, 1983.

Knopf, D. A., Koop, T., Luo, B. P., Weers, U. G., and Peter, T.: Homogeneous nucleation of NAD and NAT in liquid stratospheric aerosols: insufficient to explain denitrification, Atmos. Chem. Phys., 2, 207-214, 2002.
Middlebrook, A. M., Thomson, D. S., and Murphy, D. M.: On the purity of laboratory-generated sulfuric acid droplets and ambient particles studied by laser mass spectrometry, Aerosol Sci. Technol., 27, 293-307, 1997.

Molina, M. J., Zhang, R., Wooldridge, P. J., et al.: Physical chemistry of the $\mathrm{H} 2 \mathrm{SO} 4 / \mathrm{HNO} 3 / \mathrm{H} 2 \mathrm{O}$ system: Implications for polar stratospheric clouds, Science, 261, 1418-1423, 1993.

Salcedo, D., Molina, L. T. and Molina, M. J.: Homogeneous freezing of concentrated aqueous nitric acid solutions at polar stratospheric temperatures, J. Phys. Chem. A., 105, 1433-1439, 2001.

Tabazadeh, A., Jensen, E. J., Toon, O. B., Drdla, K. and Schoeberl, M. R.: Role of the stratospheric polar freezing belt in denitrification, Science, 291, 2591-2594, 2001.

Tabazadeh, A., Djikaev, Y. S., and Reiss, H.: Surface crystallization of supercooled water in clouds, Proc. Natl. Acad. Sci. 99, 15 873-15 878, 2002a.

Tabazadeh, A., Djikaev, Y. S., Hamill, P., and Reiss, H.: Laboratory evidence for surface nucleation of solid polar stratospheric cloud particles, J. Phys. Chem. A., 106, $10238-10246,2002$ b.

Yang, H. and Finlayson-Pitts, B. J.: Infrared spectroscopic studies of binary solutions of nitric acid and water and ternary solutions of nitric Acid, sulfuric Acid, and water at room temperature: Evidence for molecular nitric acid at the surface, J. Phys. Chem. A, 105, 1890-1896, 2001. 